\section{Study the past to divine the future. Confucius' wisdom doesn't work for idiopathic pulmonary fibrosis}

\author{
Martin Kolb, ${ }^{1}$ Gisli Jenkins, ${ }^{2}$ Luca Richeldi ${ }^{3}$
}

Predicting the future is one of the greatest challenges and for many people one of the greatest hopes of humanity. This applies to any aspect of human life and medicine included. In respiratory medicine, predicting the future is particularly difficult for chronic remodelling disorders, such as pulmonary hypertension or fibrosis. ${ }^{1}$ The course and recovery from an acute illness are usually easier to foresee than the progression and rate of decline for chronic diseases. In particular, one of the major current challenges is actually predicting the effect of the available pharmacological treatments on the course of idiopathic pulmonary fibrosis (IPF), which is of paramount importance but is still rarely possible. Nonetheless, the more we enter the era of the so-called personalised medicine, anticipating the response to a specific drug is becoming part of realistic expectations. ${ }^{2}$

Safety and efficacy of drugs are assessed in the context of placebo-controlled randomised clinical trials (RCTs). Although a well-established and worldwide accepted methodology, RCTs still have limitations: one of these is the fact that necessarily trials last for a definite period of time, for IPF typically 12 months, during which time all participants are blinded to the active treatment or to a placebo. This limitation is intrinsic and unavoidable, given the need to balance between harm and benefit when new drugs with unknown effects are tested in patients. However, once approved, all new drugs undergo a mandatory postapproval surveillance of several years. While this type of postmarketing surveillance provides valid information about long-term safety

\footnotetext{
${ }^{1}$ Department of Medicine, McMaster University and Firestone Institute for Respiratory Health, St. Joseph's HealthCare Hamilton, Hamilton, Ontario, Canada; ${ }^{2}$ Nottingham Respiratory Research Unit, University of Nottingham, Nottingham, UK; ${ }^{3} \mathrm{NIHR}$ Southampton Respiratory Biomedical Research Unit, University Hospital Southampton, Southampton, UK
}

Correspondence to Professor Luca Richeldi, National Institute for Health Research, Southampton Respiratory Biomedical Research Unit, Mailpoint 813, E Level, South Academic Block, University Hospital Southampton NHS Foundation Trust, Tremona Road, Southampton, S016 6YD, UK; I.richeldi@soton.ac.uk of new drugs, there is no formal way of assessing long-term efficacy, and even if these studies report on efficacy, they are never controlled and therefore the evidence base is less rigorous than for prospective trials. For this reason, other forms of clinical research may be used to inform clinical practice, like post hoc analyses of RCTs.

Nathan et $a l^{3}$ report the results of a post hoc analysis of the Assessment of Pirfenidone to Confirm Efficacy and Safety in Idiopathic Pulmonary Fibrosis (ASCEND) ${ }^{4}$ and Clinical Studies Assessing Pirfenidone in idiopathic pulmonary fibrosis: Research of Efficacy and Safety Outcomes (CAPACITY) ${ }^{5}$ trials, including data from more than 1200 patients with IPF. By using Pearson correlation coefficients, they found out that in the placebo group changes in FVC were only weakly correlated when measured in two consecutive 6-month intervals, thus indicating substantial variability in disease progression. Moreover, they reported that patients progressing, that is, declining $10 \%$ in their FVC or more, during treatment with pirfenidone in one given 6-month period can still benefit from treatment, in terms of lower risk of FVC decline or death, in the subsequent 6 months.

This study essentially aimed at addressing the million dollar question of how to define and identify a treatment failure in IPF, and whether and when to stop or continue a specific antifibrotic drug even when the disease is progressing. This issue is particularly relevant today, when in many areas of the world there are two approved treatments for IPF, different in their mechanisms of action and therefore potentially part of an integrated approach to the management of the disease. In this context, a switch strategy could be possible in clinical practice, in which discontinuing one drug in favour of the other is considered, once the failure of the ongoing therapy has been determined. The problem is that in fibrotic lung disorders like IPF, we still do not know how to define treatment failure. The decline of lung function over a definite period of time (typically 6 or 12 months), as measured by FVC, has been widely used to assess disease progression and risk of death in IPF, ${ }^{6}$ but its value has been questioned, ${ }^{7}$ although it has been the basis for approval of both pirfenidone and nintedanib, ${ }^{8}$ and it does not necessarily reflect the effect of therapy on an individual and hence can't define treatment failure. A recent large, although retrospective, study showed that in IPF prediction models do not predict measures of functional measures of disease progression. ${ }^{9}$ So, will this bring us back to the dispute around the validity of lung function as an endpoint in IPF trials ${ }^{7}{ }^{10}$ ? And if so, how could we use lung function to separate treatment success from failure? This same uncertainty also applies to IPF staging and definition of disease severity, which at the moment seems to be largely based on FVC but is equally arbitrary without an accepted expert consensus. ${ }^{11}$

Worldwide, drug regulatory agencies mandate their rules for the most costeffective use of drugs in clinical practice. This is crucially important to assure safety and to balance the benefits for individual patients with the overall sustainability of healthcare systems. Now that we have approved drugs, this also applies to IPF. Many national health agencies, among them the National Institute for Health and Care Excellence (NICE) in the UK, aimed at optimising the use of these new and expensive IPF treatments by defining a specific subpopulation of patients eligible for therapy, mainly by lung function levels. $^{12} 13$ Many authorities also use a so-called stopping rule, which is when a patient shows a confirmed decline in per cent predicted FVC of $10 \%$ or more in any 12 -month period. Can these limitations realistically contribute to the best use of these drugs? There are intrinsic limitations in any stopping rule for any disease progression definition. However, this is exemplified in IPF because the per cent predicted lung function is based on 'normal values' from a younger population $^{14}$ than suffer from IPF, ${ }^{15}$ and furthermore by simply calculating the decrease in FVC in absolute or relative terms different populations are identified. Therefore, this approach leads to the introduction of unjustified bias. ${ }^{16}$ Post hoc analyses of the recent phase 3 IPF trials with nintedanib showed that patients with preserved lung function (currently excluded from treatment with both drugs in the UK) benefit from treatment just as much as patients with less preserved FVC levels. ${ }^{17}$ Furthermore, this study by Nathan et al showed that by applying the stopping rule one cannot exclude precluding a future benefit in the individual patient. The 
famous saying from the Chinese philosopher Confucius, "study the past, if you would divine the future" doesn't seem to apply to predicting response to IPF therapies. However, one should always keep in mind that the rules mandated by regulators are not made to work in the individual patient but more on the community of patients as a whole. This is the basis of the current dilemma for many healthcare systems, that is, how to balance individual needs and general sustainability.

One more important question is whether post hoc evidence such as the one reported by Nathan et al is enough to challenge subgroup limitations and stopping rules such as those mandated by NICE, or whether we need real-life longitudinal prospective trials. If we accept the primacy of high-level evidence, then post hoc analysis of clinical trial data is at best hypothesis generating. Certainly, the results of this current study do not provide enough support for clinical management in real-life practice, including the decision of switching from one drug to the other or keeping patients on an 'apparently failing' drug (at least as per NICE rules). Prospective controlled trials would be needed before translating these hypotheses into clinical practice. However, this will probably never be possible without the engagement and the support of public agencies in funding the relevant studies, which are unlikely to be undertaken by commercial sponsors. There is an urgent need for initiating these studies, to allow the clinical management of patients to be driven by biomedical reasons rather than political and economic rationale. We hope that the major players in the field of biomedical research, like the National Institutes of Health in the USA and the Medical Research Council in the UK, will be willing to provide the adequate methodological and financial support to conduct such important clinical research.

Finally, we should keep in mind that in IPF the ultimate aim will be to identify the patient who is likely to respond to a given therapy, or combination of therapies, based on the molecular endotype of their condition. ${ }^{18} 19$ The pathogenesis of this disease is so complex and it is unlikely that one therapeutic compound will be enough to stop or even reverse disease progression. ${ }^{15}$ Ideally, we envision something similar to what happened in the field of AIDS, which was believed to be invariably deadly 20 years ago, while now the problem 'AIDS' has been replaced by 'HIV positivity' as long as patients are able to take and/or afford 3-4 drugs combined together. In this context, it is reassuring to see that clinical research has not come to a screeching halt after the approval of the first two antifibrotic drugs, but is ongoing and is already exploring the feasibility of combination therapies in IPF.

Contributors All authors contributed to writing this editorial.

Competing interests GJ has received Sponsored Research Agreements from GlaxoSmithKline, Novartis and Biogen, he has received lecture fees from Boehringer Ingelheim, Intermune, MedImmune and Roche and he has undertaken consultancy for Biogen, Boehringer Ingelheim, GlaxoSmithKline, Intermune, Medlmmune, Pulmatrix, PharmAkea and Roche. LR has received grants and personal fees from Intermune, and personal fees from Boehringer Ingelheim, Intermune, Medlmmune, Biogen, Sanofi-Aventis Roche, Takeda, ImmuneWorks and Shionogi. MK: none declared.

Provenance and peer review Commissioned; internally peer reviewed.

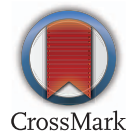

To cite Kolb M, Jenkins G, Richeldi L. Thorax 2016;71:399-400.

Published Online First 11 April 2016

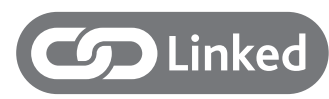

- http://dx.doi.org/10.1136/thoraxjnl-2015-207011

Thorax 2016;71:399-400.

doi:10.1136/thoraxjnl-2016-208670

\section{REFERENCES}

1 Ask K, Kolb MR. Drug development for chronic lung disease-mission impossible? Respirology 2014;20:13-14.

2 Hambly N, Shimbori C, Kolb M. Molecular classification of idiopathic pulmonary fibrosis: personalized medicine, genetics and biomarkers. Respirology 2015;20:1010-22.

3 Nathan S, Albera C, Bradford WZ, et al. Effect of continued treatment with pirfenidone following clinically meaningful declines in forced vital capacity: analysis of data from three phase 3 trials in 3 patients with idiopathic pulmonary fibrosis. Thorax 2016;71:429-35.

4 King TE Jr, Bradford WZ, Castro-Bernardini S, et al. A phase 3 trial of pirfenidone in patients with idiopathic pulmonary fibrosis. N Engl I Med 2014;370:2083-92.

5 Noble PW, Albera C, Bradford WZ, et al. Pirfenidone in patients with idiopathic pulmonary fibrosis (CAPACITY): two randomised trials. Lancet 2011;377:1760-9.

6 du Bois RM, Weycker D, Albera C, et al. Ascertainment of individual risk of mortality for patients with idiopathic pulmonary fibrosis (IPF). Am J Respir Crit Care Med 2011;184:459-66.

7 Raghu G, Collard HR, Anstrom KJ, et al. Idiopathic pulmonary fibrosis: clinically meaningful primary endpoints in phase 3 clinical trials. Am J Respir Crit Care Med 2012;185:1044-8.

8 Karimi-Shah BA, Chowdhury BA. Forced vital capacity in idiopathic pulmonary fibrosis--FDA review of pirfenidone and nintedanib. N Engl J Med 2015;372:1189-91.

9 Ley B, Bradford WZ, Vittinghoff E, et al. Predictors of mortality poorly predict common measures of disease progression in idiopathic pulmonary fibrosis. Am J Respir Crit Care Med Published Online First: $3 \mathrm{Mar}$ 2016. doi:10.1164/rccm.201508-15460C

10 du Bois RM, Nathan SD, Richeldi L, et al. Idiopathic pulmonary fibrosis: lung function is a clinically meaningful endpoint for phase III trials. Am J Respir Crit Care Med 2012;186:712-15.

11 Kolb M, Collard HR. Staging of idiopathic pulmonary fibrosis: past, present and future. Eur Respir Rev 2014;23:220-4.

12 Landells LJ, Naidoo B, Robertson J, et al. NICE guidance on pirfenidone for treating idiopathic pulmonary fibrosis. Lancet Respiratory 2013;1:191-2.

13 Laurenson S, Sidhu R, Goodall M, et al. NICE guidance on nintedanib for treating idiopathic pulmonary fibrosis. Lancet Respir Med 2016:4:176-7.

14 Quanjer PH, Tammeling GJ, Cotes JE, et al. Lung volumes and forced ventilatory flows. Report Working Party Standardization of Lung Function Tests, European Community for Steel and Coal. Official Statement of the European Respiratory Society. Eur Respir J Supp/ 1993;16:5-40.

15 Jenkins RG, Simpson JK, Saini G, et al. Longitudinal change in collagen degradation biomarkers in idiopathic pulmonary fibrosis: an analysis from the prospective, multicentre PROFILE study. Lancet Respir Med 2015;3:462-72.

16 Richeldi L, Ryerson CJ, Lee JS, et al. Relative versus absolute change in forced vital capacity in idiopathic pulmonary fibrosis. Thorax 2012;67:407-11.

17 Costabel U, Inoue Y, Richeldi L, et al. Efficacy of nintedanib in idiopathic pulmonary fibrosis across pre-specified subgroups in INPULSIS. Am J Respir Crit Care Med 2016;193:178-85.

18 Goodwin AT, Jenkins G. Molecular endotyping of pulmonary fibrosis. Chest 2016;149:228-37.

19 Brownell R, Kaminski N, Woodruff PG, et al. Precision medicine: the new frontier in idiopathic pulmonary fibrosis. Am J Respir Crit Care Med First published online 18 Mar 2016 as doi:10.1164/rccm. 201601-0169Cl 